\title{
The Essential Transcriptional Function of BRD4 in Acute Myeloid Leukemia
}

\author{
JAe-Seok Roe And Christopher R. VAKOC \\ Cold Spring Harbor Laboratory, Cold Spring Harbor, New York 11724 \\ Correspondence:vakoc@cshl.edu
}

\begin{abstract}
Acute myeloid leukemia (AML) is often initiated by genetic alterations of machineries that regulate chromatin and transcription, thereby blocking cell differentiation. Such mechanisms may also render leukemia cells vulnerable to perturbations of transcriptional regulators, which includes small molecules targeting the coactivator protein BRD4. Numerous studies have validated BRD4 as a therapeutic target in diverse subtypes of AML; however, the vital function of BRD4 in this disease is only beginning to be understood. Here we discuss the recent progress in elucidating the transcriptional function of BRD4 in AML cells, with an emphasis on the desirable attributes, but also the inherent limitations, of targeting general coactivator proteins as cancer therapy.
\end{abstract}

Chromatin alterations are intimately linked with the control of transcription, and such processes are commonly deregulated in the pathogenesis of cancer (Dawson and Kouzarides 2012). This is highlighted by many largescale cancer genome studies, which have identified frequent mutations in the genes encoding chromatin regulators during tumor evolution (Garraway and Lander 2013). Although the majority of mutations in chromatin regulators found in cancer are predicted to be loss-of-function, a smaller subset of these mutations result in a gain of function that drives oncogenic gene expression. In addition, unmutated chromatin regulators can support the function of other oncoproteins to drive tumorigenesis, thereby acting as nononcogene dependencies in cancer. Thus, cancer cells are often addicted to certain chromatin regulators, which represent viable targets for direct therapeutic intervention in this disease (Shen and Vakoc 2015).

Acute myeloid leukemia (AML) was one of the first malignancies in which genes encoding chromatin regulators were identified as drivers of cell transformation, and therefore AML serves as a paradigm for studying chromatin deregulation in cancer (Greenblatt and Nimer 2014; Wouters and Delwel 2016). As an example, the histone H3 lysine 4 methyltransferase protein MLL (also known as KMT2A) is often altered in AML via chromosomal translocations or mutations, thereby deregulating chromatin to cause a blockade in myeloid maturation (Krivtsov and Armstrong 2007). Other commonly mutated genes in AML include DNMT3A or TET2, which encode enzymes involved in DNA methylation and demethylation, respectively (Delhommeau et al. 2009; Ley et al. 2010). Genetic alterations of transcription factors (TFs) are also common in AML and lead to indirect alterations of chromatin structure and function to initiate disease progression (Rosenbauer and Tenen 2007).
The widespread involvement of aberrant chromatin states in AML provides a rationale to explore the use of chromatin modulating therapeutics in this disease. One of the first examples of such an agent is 5-azacytidine, which inhibits DNA methyltransferases. 5-Azacytidine and other related molecules are approved therapies in AML management, despite uncertainty regarding the mechanisms underlying their therapeutic efficacy (Silverman et al. 2002; Kantarjian et al. 2006; Issa et al. 2015). A major effort in the field in recent years has been to uncover other epigenetic vulnerabilities in AML, which has culminated in recently initiated clinical trials evaluating inhibitors of histone modifying enzymes (DOT1L and LSD1) and inhibitors of the chromatin reader protein BRD4 (Bernt et al. 2011; Nguyen et al. 2011; Harris et al. 2012). Here, we will review our current understanding of BRD4 as therapeutic target in AML.

\section{BRD4 IS A DEPENDENCY AND A THERAPEUTIC TARGET IN AML}

BRD4 can be classified as a chromatin reader protein, as it contains two tandem bromodomain modules that engage in acetyllysine recognition to tether BRD4 to chromatin (Wu and Chiang 2007). BRD4 can also be classified as a transcriptional coactivator, as it can bind directly (or indirectly) to TFs to promote downstream effects on RNA polymerase II (Pol II) activation (Shi and Vakoc 2014). Most of the available evidence suggests that BRD4 functions as a scaffold protein that links acetylated histones and TFs with the local assembly of the transcriptional apparatus at specific cis-regulatory elements. However, it was recently proposed that BRD4 employs intrinsic kinase and acetyltransferase activities,

(C) 2016 Roe and Vakoc. This article is distributed under the terms of the Creative Commons Attribution-NonCommercial License, which permits reuse and redistribution, except for commercial purposes, provided that the original author and source are credited. 
although the functional relevance of these activities to the transcriptional function of BRD4 remains to be validated (Devaiah et al. 2012, 2016). Studies over nearly the past 20 years have implicated BRD4 in numerous cellular processes, including the regulation of transcription, DNA replication, and DNA repair ( $\mathrm{Wu}$ and Chiang 2007; Floyd et al. 2013).

Although it might have been assumed that BRD4 performs a general role in regulating genomic processes, several groups identified small-molecule inhibitors of BRD4 bromodomains (and its closest homologs BRD2/ BRD3/BRDT) in cell-based screens evaluating for discrete biological effects reviewed in Filippakopoulos et al. 2010; Nicodeme et al. (2010). These small molecules were found to bind to the bromodomains in a competitive manner with acetyllysine, and hence result in the release of BRD4 and its homologs (which are often referred to as the bromodomain and extraterminal domain-containing proteins, or BET protein family) from cellular chromatin. Since the description of these molecules in 2010, numerous studies have shown that chemical inhibition of BET proteins results in gene-specific effects on transcription, which are distinct from global transcription inhibition (Shi and Vakoc 2014). The specificity of transcriptional and cellular effects of BET inhibition has also allowed an investigation of disease-specific roles of BRD4, particularly in cancer.

In 2011, several independent groups showed that BET inhibitors exhibit anti-AML activity in animal models of this disease (Dawson et al. 2011; Mertz et al. 2011; Zuber et al. 2011b). One of these studies was from our own laboratory, in which we identified BRD4 using a shorthairpin RNA (shRNA) screen that evaluated the essentiality of chromatin regulators for disease progression in a mouse model of AML initiated by the MLL-AF9 and Nras ${ }^{\text {G12D }}$ oncogenes (Zuber et al. 2011b). This screen identified BRD4 as a top vulnerability in this disease, based on the overall potency of the growth-arrest phenotype observed following BRD4 knockdown. Notably, a modest fourfold knockdown of BRD4 is sufficient to trigger terminal differentiation and apoptosis in AML cells, whereas BRD4 knockdown only elicited cytostatic effects in other immortalized cell types. Through a collaboration with James Bradner's laboratory, we obtained the BET inhibitor JQ1 and showed that the phenotypic consequences observed upon BRD4 knockdown were faithfully recapitulated following exposure to nanomolar concentrations of this compound. The close similarity in the effects of BRD4 knockdown and JQ1 exposure at the phenotypic and global transcriptional level provided strong support that BRD4 was the relevant target underlying the effects of JQ1 in this cell type (Zuber et al. 2011b). Most notably, intraperitoneal injection of JQ1 into AML-bearing animals was shown to delay disease progression in vivo at doses that showed minimal effects on normal hematopoiesis. Although our mechanistic understanding of these effects was limited during the early stages of this research, two observations were made at this time that would come to shape our mechanistic evaluation of BRD4 in AML. First, the sensitivity to JQ1 was identified in MLL-rearranged subtype of AML but was equally apparent in the other diverse genetic subtypes of this disease. Second, JQ1 caused a rapid, and pronounced, suppression of c-Myc transcription in AML cells, whereas Myc expression was unaffected by JQ1 in immortalized fibroblasts. Collectively, these experiments led us to propose that BRD4 was a novel epigenetic target in AML and highlighted the utility of genetic screening to nominate therapeutic opportunities in cancer.

An independent study from the laboratory of Tony Kouzarides published at the same time also showed the efficacy of BET inhibitors in the MLL-rearranged subtype of AML (Dawson et al. 2011). In this study, a series of proteomic screens performed in AML nuclear lysates had found BET proteins in association with the transcription elongation regulators $\mathrm{PAF}$ and $\mathrm{P}-\mathrm{TEFb}$, which are known interacting partners of MLL-fusion oncoproteins (Muntean et al. 2010; Yokoyama et al. 2010). These findings motivated an evaluation of the BET inhibitor I-BET, which inhibits BET bromodomains in a similar manner to JQ1, in various preclinical models of the MLL-fusion subtype of AML. I-BET was shown to suppress AML progression in these models, in association with transcriptional suppression of MYC, BCL2, and CDK6 (Dawson et al. 2011). Although it is unlikely that BET proteins act directly to support the function of MLL-fusion proteins, this work provided strong evidence supporting BET proteins as therapeutic targets in AML. The laboratory of Robert Sims at Constellation Pharmaceuticals also showed independently that human AML cell lines are sensitive to JQ1 in association with transcriptional suppression of MYC (Mertz et al. 2011). Collectively, these convergent studies showed that diverse subtypes of AML are vulnerable to BRD4 inhibition, and set the stage for evaluation of BET inhibitors as AML therapy in early stage clinical trials.

Clinical studies were initiated in 2013 to evaluate the effect of BET inhibitors in human cancer patients. The first Phase I study of a BET bromodomain inhibitor (called OTX-015) in leukemia patients was published in 2016 (Berthon et al. 2016). This dose escalation study evaluated OTX-015 in relapsed-refractory acute leukemia patients. This study provided the first glimpse into the toxicities of BET inhibition in humans, which includes reduced platelet counts, gastrointestinal symptoms, fatigue, and altered levels of coagulation factors, and hence led to the identification of suitable dosing regimens for future clinical investigation. Clinical responses were identified in a subset of patients treated on this trial at doses that were near or below the maximum tolerated dose, with a subset of patients achieving a complete remission. However, all of these patients showing a complete remission eventually relapsed while receiving therapy (Berthon et al. 2016). Although this study provides encouraging support for BET inhibition as a therapeutic strategy in human AML, numerous challenges remain in identifying predictive correlates of BET inhibitor sensitivity and in determining optimal combination drug regimens to make responses more durable. It should be emphasized that sensitivity to BET inhibition is not limited to AML but has also been established in lymphoid 
neoplasms, including lymphoma, B- and T-cell leukemias, multiple myeloma, and various solid tumors, which are indications under investigation in clinical trials (Cai et al. 2015).

One of the clear challenges to BET inhibitor therapy in AML will be the rapid emergence of drug-resistant cells. Recent studies have dissected the molecular mechanisms of resistance BET inhibition in AML mouse models, which have implicated nongenetic mechanisms (Fong et al. 2015; Rathert et al. 2015). Instead, it appears that cells with reprogrammed transcriptional states can be selected for in the presence of BET inhibition that are able to bypass the essential function of BRD4 to sustain growthpromoting genes, such as Myc. One of these BRD4-bypass pathways is via the WNT signaling pathway and suggests that dual targeting BRD4 and WNT could lead to durable therapeutic responses (Rathert et al. 2015). Numerous studies have identified effective BET inhibitor drug synergies, including combinations of BET inhibitors with FLT3 kinase inhibitors in cells harboring activating mutations of FLT3 (Fiskus et al. 2014). This study also suggests that resistance to FLT3 inhibition might be overcome by targeting BET proteins. In the MLL-fusion subtype of AML, co-inhibition of BRD4 and DOT1L can also lead to synergistic antileukemia responses (Gilan et al. 2016). These studies highlight how an expanding body of basic and translational research strategies can inform how BET inhibitors proceed in future clinical trials.

Despite the speed in which BET inhibitors have moved into clinical evaluation, it remains unknown why chemical inhibition of a general coactivator protein like BRD4 leads to therapeutic effects in AML. At the heart of this issue is the deficiency in our understanding of the leukemia maintenance function of BRD4, which has been the subject of intense investigation over the past 5 years. Below, we summarize our efforts, and those of other laboratories, in characterizing the essential transcriptional function of BRD4 in AML.

\section{HEMATOPOIETIC LINEAGE TRANSCRIPTION FACTORS USE BRD4 AS A COFACTOR}

The central hypothesis in the field regarding the therapeutic index of BET inhibitors in cancer is that targeting BRD4 disproportionately suppresses cancer-promoting genes versus other gene classes. The mechanisms that underlie this gene specificity are not well understood but may relate to the manner in which BRD4 is recruited to chromatin. ChIP-seq analysis in murine MLL-AF9/ Nras ${ }^{\mathrm{G} 12 \mathrm{D}}$-transformed AML cells revealed that BRD4 tends to occupy acetylated nucleosomes, as well as nucleosome-free regions across genome (Roe et al. 2015). The presence of BRD4 at nucleosome depleted sites implicated the possibility that transcription factors were involved in this process. Indeed, prior work had implicated BET proteins in recognizing acetylated transcription factors GATA-1, NF- $\mathrm{B}$, and Twist in other cellular contexts (Lamonica et al. 2011; Shi et al. 2014). Using an analysis of overrepresented motifs at BRD4-occupied sites in leu- kemia cells, it was found that the TFs ERG, FLI1, PU.1, $\mathrm{C} / \mathrm{EBP} \alpha, \mathrm{C} / \mathrm{EBP} \beta$, and MYB are highly correlated with BRD4 in this cell type (Roe et al. 2015). Notably, each of these TFs are lineage determinants that are vital for normal hematopoietic stem and progenitor cells (Zhang et al. 1997; Fisher and Scott 1998; Spyropoulos et al. 2000; Hirai et al. 2006; Greig et al. 2008; Loughran et al. 2008). Ectopic expression of these TFs in heterologous cell types (fibroblasts) will reprogram BRD4 to the unique binding sites found in leukemia cells, which suggests that TFs, either directly or indirectly, promote BRD4 recruitment to the genome in AML (Roe et al. 2015).

The mechanism by which these hematopoietic TFs stimulate BRD4 recruitment is via the use of the lysine acetyltransferase p300 as a coactivator, which prior work had shown can bind to each of these TFs (Dai et al. 1996; Parker et al. 1999; Yamamoto et al. 1999; Tomita et al. 2000; Erickson et al. 2001; Sano and Ishii 2001; Bai et al. 2005; Sandberg et al. 2005; Cesena et al. 2007; Li et al. 2011; Schlottmann et al. 2012; Roe et al. 2015). Genetic targeting and chemical inhibition of p300 in AML closely phenocopies the transcriptional effects of BRD4 knockdown and leads to the release of BRD4 from chromatin (Roe et al. 2015). Not only is p300 recruited to chromatin by these TFs, but it can also acetylate each of these TFs at functionally important sites (Tomita et al. 2000; Erickson et al. 2001; Bai et al. 2005; Cesena et al. 2007; Schlottmann et al. 2012; Blee et al. 2016). We characterized one of these sites on ERG in detail, which is a KGGK motif that can be acetylated by p300 one both lysines. The diacetylated ERG peptide can bind directly to BRD4 and is likely to contribute to BRD4 tethering to the AML genome. However, it is likely that multiple TFs and histones associate with BRD4 via low-affinity interactions to account for its recruitment. Collectively, our study showed the critical role of hematopoietic lineage TFs in using BRD4 as a cofactor to promote transcriptional activation in AML.

\section{NSD3, CHD8, MEDIATOR, AND P-TEFb ARE EFFECTORS OF BRD4 IN AML CELLS}

Another key aspect of BRD4 function in AML concerns the downstream mechanisms by which this regulator activates RNA polymerase II. Proteomic studies have repeatedly shown that BRD4 engages in numerous protein-protein interactions and thus acts as a scaffold for other regulators. One BRD4-interacting partner is the kinase complex P-TEFb, which consists of $\mathrm{Cdk} 9$ and a cyclin subunit (Jang et al. 2005; Yang et al. 2005). PTEFb phosphorylates the pausing factors DSIF and NELF, as well as RNA polymerase II itself to promote transcription elongation (Peterlin and Price 2006). Studies in AML and in various other cell types have shown that JQ1 promotes the rapid eviction of P-TEFb from chromatin in parallel with an accumulation of paused RNA polymerase at nearby genes (Loven et al. 2013; Bhagwat et al. 2016). Moreover, CRISPR exon scanning experiments have revealed that the carboxy-terminal motif of BRD4, which engages in a direct interaction with 
$\mathrm{P}-\mathrm{TEFb}$, is also vital for AML cell proliferation (Bisgrove et al. 2007; Shi et al. 2015).

Multiple subunits of the Mediator complex can also bind to BRD4 (Jiang et al. 1998; Donner et al. 2010). Although the MED23 subunit of Mediator appears to be required for the BRD4 interaction, the precise binding surface that links these two factors has yet to be mapped (Wang et al. 2013). In AML and in other cell types, BRD4 occupancy across the genome is tightly correlated with the Mediator complex, with JQ1 releasing Mediator complexes from chromatin (Donner et al. 2010; Loven et al. 2013; Bhagwat et al. 2016). In addition, genetic targeting of certain Mediator subunits in AML cells, such as MED12, MED13, MED23, and MED24 will lead to a similar differentiation phenotype and transcriptional alterations as observed upon targeting BRD4 (Bhagwat et al. 2016). Mediator is also known to regulate P-TEFb activity via its head module (Conaway and Conaway 2013), which leads to the coordination, and perhaps synergy, between these two positive regulators of RNA polymerase II activity (Allen and Taatjes 2015).

One of the defining domains of all four BET proteins is the extraterminal (ET) domain, which has been shown to activate transcription when artificially tethered to a minimal promoter (Shen et al. 2015). In AML cells, the ET domain physically associates with a short isoform of NSD3, which acts as an adaptor protein that couples BRD4 with the CHD8 chromatin remodeler (Shen et al. 2015). Notably, genetic targeting of NSD3 or CHD8 leads to similar phenotypes and transcriptional effects as observed upon BRD4 inhibition (Shen et al. 2015). Collectively, these studies highlight how BRD4 uses several interacting partners to facilitate chromatin remodeling and transcriptional activation in AML cells.

Although BRD4-containing protein complexes are broadly associated with active promoters and enhancers across the AML genome, JQ1 leads to the disproportionate eviction of these complexes from specific cis elements (Loven et al. 2013; Shi et al. 2013). This includes a distal cluster of enhancers (or super-enhancer) at the Myc locus, thus accounting for the hypersensitivity of $M y c$ transcription to BRD4 inhibition in AML (Shi et al. 2013; Bhagwat et al. 2016). Remarkably, the locations of severe BRD4 eviction following JQ1 exposure are highly correlated with genes having pro-leukemic functions, as revealed through gene ontology analysis (Bhagwat et al. 2016). Moreover, these cis elements are skewed in having more Myb occupancy than the other hematopoietic TFs described above (Bhagwat et al. 2016). This result implies that Myb is more suppressed by JQ1 than other hematopoietic TFs, which might be a contributor to the overall sensitivity of leukemia cells to JQ1, because prior studies have shown that AML cells are more sensitive to Myb suppression than normal myeloid cells (Anfossi et al. 1989; Calabretta et al. 1991; Zuber et al. 2011a). These findings suggest that biased release of BRD4 complexes for specific cis elements is a key determinant of the gene-specific transcriptional effects of BET bromodomain inhibition.

One key question yet to be addressed is why some cis elements are more sensitive than others to JQ1. One pos- sibility is that clustered enhancers recruit BRD4 in a cooperative fashion, which is more vulnerable to chemical inhibition than sites lacking cooperative BRD4 recruitment (Loven et al. 2013). Another possibility is that many sites in the genome recruit BRD4 in a bromodomain-independent manner and hence resist JQ1-mediated displacement. A third possibility is that specific cis elements show highly dynamic ON-OFF rates of BRD4 recruitment, which consequently are preferentially evicted by JQ1 when compared with more static cis elements. Regardless of the underlying mechanism, the skewed pattern of BRD4 release from the genome from leukemiarelevant genes is the clearest mechanism to date that accounts for the therapeutic index of BET inhibitors in AML.

\section{CONCLUSION}

Mechanistic studies of BRD4 in the MLL-fusion subtype of AML have unexpectedly revealed that this regulator is almost entirely engaged as a cofactor for hematopoietic lineage transcription factors, and not via an association with the MLL-fusion oncoprotein (Roe et al. 2015). Thus, the antileukemia activity of JQ1 occurs despite the output of MLL-fusion oncoproteins being unperturbed. Thus, targeting BRD4 in AML may share more in common conceptually with targeting lineagespecific TFs in prostate (androgen receptor) and breast (estrogen receptor) cancers (Bhagwat and Vakoc 2015). However, it must be recognized that, unlike AR and ER examples, BRD4 is likely to function as a key coactivator in all human tissues, and hence the largest concern for BET inhibitors as therapeutics lies in their potential for undesirable toxicities, which is just beginning to be exposed in clinical trials (Amorim et al. 2016; Berthon et al. 2016). A key priority for future investigation will be to expose coactivator perturbations that are capable of achieving potent anticancer activity while minimizing the broad suppression of multiple TFs. In AML, this would best be achieved by targeting coactivators in a manner that suppresses Myb function while preserving other vital TFs for normal hematopoiesis. Continued efforts aimed at defining the fundamental interaction between TFs and coactivators might expose improved modalities to reprogram transcription in a manner suitable for therapeutic efficacy in cancer.

\section{ACKNOWLEDGMENTS}

C.R.V. is supported by the Leukemia and Lymphoma Society, the Burroughs-Wellcome Fund, the Pershing Square Sohn Cancer Research Alliance, the Starr Cancer Consortium, and the National Institutes of Health (NIH)/ National Cancer Institute (NCI) grants RO1 CA174793 and 5P01CA013106.

\section{REFERENCES}

Allen BL, Taatjes DJ. 2015. The Mediator complex: A central integrator of transcription. Nat Rev Mol Cell Biol 16: 155166. 
Amorim S, Stathis A, Gleeson M, Iyengar S, Magarotto V, Leleu $\mathrm{X}$, Morschhauser F, Karlin L, Broussais F, Rezai K, et al. 2016. Bromodomain inhibitor OTX015 in patients with lymphoma or multiple myeloma: A dose-escalation, open-label, pharmacokinetic, phase 1 study. Lancet Haematol 3: e196e204.

Anfossi G, Gewirtz AM, Calabretta B. 1989. An oligomer complementary to c-myb-encoded mRNA inhibits proliferation of human myeloid leukemia cell lines. Proc Natl Acad Sci 86: 3379-3383.

Bai Y, Srinivasan L, Perkins L, Atchison ML. 2005. Protein acetylation regulates both PU.1 transactivation and $\operatorname{Ig} \kappa 3^{\prime}$ enhancer activity. $J$ Immunol 175: 5160-5169.

Bernt KM, Zhu N, Sinha AU, Vempati S, Faber J, Krivtsov AV, Feng Z, Punt N, Daigle A, Bullinger L, et al. 2011. MLLrearranged leukemia is dependent on aberrant $\mathrm{H} 3 \mathrm{~K} 79$ methylation by DOT1L. Cancer Cell 20: 66-78.

Berthon C, Raffoux E, Thomas X, Vey N, Gomez-Roca C, Yee K, Taussig DC, Rezai K, Roumier C, Herait P, et al. 2016. Bromodomain inhibitor OTX015 in patients with acute leukaemia: A dose-escalation, phase 1 study. Lancet Haematol 3: e186-e195.

Bhagwat AS, Vakoc CR. 2015. Targeting transcription factors in cancer. Trends Cancer 1: 53-65.

Bhagwat AS, Roe JS, Mok BY, Hohmann AF, Shi J, Vakoc CR. 2016. BET bromodomain inhibition releases the Mediator complex from select cis-regulatory elements. Cell Rep 15: 519-530.

Bisgrove DA, Mahmoudi T, Henklein P, Verdin E. 2007. Conserved P-TEFb-interacting domain of BRD4 inhibits HIV transcription. Proc Natl Acad Sci 104: 13690-13695.

Blee AM, Liu S, Wang L, Huang H. 2016. BET bromodomainmediated interaction between ERG and BRD4 promotes prostate cancer cell invasion. Oncotarget 7: 38319-38332.

Cai SF, Chen CW, Armstrong SA. 2015. Drugging chromatin in cancer: Recent advances and novel approaches. Mol Cell 60: $561-570$.

Calabretta B, Sims RB, Valtieri M, Caracciolo D, Szczylik C, Venturelli D, Ratajczak M, Beran M, Gewirtz AM. 1991. Normal and leukemic hematopoietic cells manifest differential sensitivity to inhibitory effects of c-myb antisense oligodeoxynucleotides: An in vitro study relevant to bone marrow purging. Proc Natl Acad Sci 88: 2351-2355.

Cesena TI, Cardinaux JR, Kwok R, Schwartz J. 2007. CCAAT/ enhancer-binding protein $(\mathrm{C} / \mathrm{EBP}) \beta$ is acetylated at multiple lysines: Acetylation of $\mathrm{C} / \mathrm{EBP} \beta$ at lysine 39 modulates its ability to activate transcription. J Biol Chem 282: 956-967.

Conaway RC, Conaway JW. 2013. The Mediator complex and transcription elongation. Biochim Biophys Acta 1829: 69-75.

Dai P, Akimaru H, Tanaka Y, Hou DX, Yasukawa T, Kanei-Ishii C, Takahashi T, Ishii S. 1996. CBP as a transcriptional coactivator of c-Myb. Genes Dev 10: 528-540.

Dawson MA, Kouzarides T. 2012. Cancer epigenetics: From mechanism to therapy. Cell 150: $12-27$.

Dawson MA, Prinjha RK, Dittmann A, Giotopoulos G, Bantscheff M, Chan WI, Robson SC, Chung CW, Hopf C, Savitski $\mathrm{MM}$, et al. 2011. Inhibition of BET recruitment to chromatin as an effective treatment for MLL-fusion leukaemia. Nature 478: $529-533$.

Delhommeau F, Dupont S, Della Valle V, James C, Trannoy S, Masse A, Kosmider O, Le Couedic JP, Robert F, Alberdi A, et al. 2009. Mutation in TET2 in myeloid cancers. $N$ Engl $J$ Med 360: 2289-2301.

Devaiah BN, Lewis BA, Cherman N, Hewitt MC, Albrecht BK, Robey PG, Ozato K, Sims RJ III, Singer DS. 2012. BRD4 is an atypical kinase that phosphorylates serine 2 of the RNA polymerase II carboxy-terminal domain. Proc Natl Acad Sci 109: 6927-6932.

Devaiah BN, Case-Borden C, Gegonne A, Hsu CH, Chen Q, Meerzaman D, Dey A, Ozato K, Singer DS. 2016. BRD4 is a histone acetyltransferase that evicts nucleosomes from chromatin. Nat Struct Mol Biol 23: 540-548.
Donner AJ, Ebmeier CC, Taatjes DJ, Espinosa JM. 2010. CDK8 is a positive regulator of transcriptional elongation within the serum response network. Nat Struct Mol Biol 17: 194-201.

Erickson RL, Hemati N, Ross SE, MacDougald OA. 2001. p300 coactivates the adipogenic transcription factor CCAAT/enhancer-binding protein $\alpha . J$ Biol Chem 276: 16348-16355.

Filippakopoulos P, Qi J, Picaud S, Shen Y, Smith WB, Fedorov O, Morse EM, Keates T, Hickman TT, Felletar I, et al. 2010. Selective inhibition of BET bromodomains. Nature 468: 1067-1073.

Fisher RC, Scott EW. 1998. Role of PU.1 in hematopoiesis. Stem Cells 16: $25-37$.

Fiskus W, Sharma S, Qi J, Shah B, Devaraj SG, Leveque C, Portier BP, Iyer S, Bradner JE, Bhalla KN. 2014. BET protein antagonist JQ1 is synergistically lethal with FLT3 tyrosine kinase inhibitor (TKI) and overcomes resistance to FLT3TKI in AML cells expressing FLT-ITD. Mol Cancer Ther 13: $2315-2327$

Floyd SR, Pacold ME, Huang Q, Clarke SM, Lam FC, Cannell IG, Bryson BD, Rameseder J, Lee MJ, Blake EJ, et al. 2013. The bromodomain protein Brd4 insulates chromatin from DNA damage signalling. Nature 498: 246-250.

Fong CY, Gilan O, Lam EY, Rubin AF, Ftouni S, Tyler D, Stanley K, Sinha D, Yeh P, Morison J, et al. 2015. BET inhibitor resistance emerges from leukaemia stem cells. $\mathrm{Na}$ ture 525: 538-542.

Garraway LA, Lander ES. 2013. Lessons from the cancer genome. Cell 153: 17-37.

Gilan O, Lam EY, Becher I, Lugo D, Cannizzaro E, Joberty G, Ward A, Wiese M, Fong CY, Ftouni S, et al. 2016. Functional interdependence of BRD4 and DOT1L in MLL leukemia. Nat Struct Mol Biol 23: 673-681.

Greenblatt SM, Nimer SD. 2014. Chromatin modifiers and the promise of epigenetic therapy in acute leukemia. Leukemia 28: $1396-1406$.

Greig KT, Carotta S, Nutt SL. 2008. Critical roles for c-Myb in hematopoietic progenitor cells. Semin Immunol 20: 247-256.

Harris WJ, Huang X, Lynch JT, Spencer GJ, Hitchin JR, Li Y, Ciceri F, Blaser JG, Greystoke BF, Jordan AM, et al. 2012. The histone demethylase KDM1A sustains the oncogenic potential of MLL-AF9 leukemia stem cells. Cancer Cell 21: $473-487$

Hirai H, Zhang P, Dayaram T, Hetherington CJ, Mizuno S, Imanishi J, Akashi K, Tenen DG. 2006. C/EBP $\beta$ is required for 'emergency' granulopoiesis. Nat Immunol 7: 732-739.

Issa JP, Roboz G, Rizzieri D, Jabbour E, Stock W, O'Connell C, Yee K, Tibes R, Griffiths EA, Walsh K, et al. 2015. Safety and tolerability of guadecitabine (SGI-110) in patients with myelodysplastic syndrome and acute myeloid leukaemia: A multicentre, randomised, dose-escalation phase 1 study. Lancet Oncol 16: 1099-1110.

Jang MK, Mochizuki K, Zhou M, Jeong HS, Brady JN, Ozato K. 2005. The bromodomain protein Brd4 is a positive regulatory component of P-TEFb and stimulates RNA polymerase IIdependent transcription. Mol Cell 19: 523-534.

Jiang YW, Veschambre P, Erdjument-Bromage H, Tempst P, Conaway JW, Conaway RC, Kornberg RD. 1998. Mammalian mediator of transcriptional regulation and its possible role as an end-point of signal transduction pathways. Proc Natl Acad Sci 95: $8538-8543$.

Kantarjian H, Issa JP, Rosenfeld CS, Bennett JM, Albitar M, DiPersio J, Klimek V, Slack J, de Castro C, Ravandi F, et al. 2006. Decitabine improves patient outcomes in myelodysplastic syndromes: Results of a phase III randomized study. Cancer 106: 1794-1803.

Krivtsov AV, Armstrong SA. 2007. MLL translocations, histone modifications and leukaemia stem-cell development. Nat Rev Cancer 7: 823-833.

Lamonica JM, Deng W, Kadauke S, Campbell AE, Gamsjaeger R, Wang H, Cheng Y, Billin AN, Hardison RC, Mackay JP, et al. 2011. Bromodomain protein Brd3 associates with acetylated GATA1 to promote its chromatin occupancy at erythroid target genes. Proc Natl Acad Sci 108: E159-E168. 
Ley TJ, Ding L, Walter MJ, McLellan MD, Lamprecht T, Larson DE, Kandoth C, Payton JE, Baty J, Welch J, et al. 2010. DNMT3A mutations in acute myeloid leukemia. $N$ Engl $J$ Med 363: 2424-2433.

Li Y, Kong D, Wang Z, Ahmad A, Bao B, Padhye S, Sarkar FH. 2011. Inactivation of AR/TMPRSS2-ERG/Wnt signaling networks attenuates the aggressive behavior of prostate cancer cells. Cancer Prev Res (Phila) 4: 1495-1506.

Loughran SJ, Kruse EA, Hacking DF, de Graaf CA, Hyland CD, Willson TA, Henley KJ, Ellis S, Voss AK, Metcalf D, et al. 2008. The transcription factor Erg is essential for definitive hematopoiesis and the function of adult hematopoietic stem cells. Nat Immunol 9: 810-819.

Loven J, Hoke HA, Lin CY, Lau A, Orlando DA, Vakoc CR, Bradner JE, Lee TI, Young RA. 2013. Selective inhibition of tumor oncogenes by disruption of super-enhancers. Cell 153: $320-334$

Mertz JA, Conery AR, Bryant BM, Sandy P, Balasubramanian S, Mele DA, Bergeron L, Sims RJ III. 2011. Targeting MYC dependence in cancer by inhibiting BET bromodomains. Proc Natl Acad Sci 108: 16669-16674.

Muntean AG, Tan J, Sitwala K, Huang Y, Bronstein J, Connelly JA, Basrur V, Elenitoba-Johnson KS, Hess JL. 2010. The PAF complex synergizes with MLL fusion proteins at HOX loci to promote leukemogenesis. Cancer Cell 17: 609-621.

Nguyen AT, Taranova O, He J, Zhang Y. 2011. DOT1L, the H3K79 methyltransferase, is required for MLL-AF9-mediated leukemogenesis. Blood 117: 6912-6922.

Nicodeme E, Jeffrey KL, Schaefer U, Beinke S, Dewell S, Chung CW, Chandwani R, Marazzi I, Wilson P, Coste H, et al. 2010. Suppression of inflammation by a synthetic histone mimic. Nature 468: 1119-1123.

Parker D, Rivera M, Zor T, Henrion-Caude A, Radhakrishnan I, Kumar A, Shapiro LH, Wright PE, Montminy M, Brindle PK. 1999. Role of secondary structure in discrimination between constitutive and inducible activators. Mol Cell Biol 19: $5601-$ 5607.

Peterlin BM, Price DH. 2006. Controlling the elongation phase of transcription with P-TEFb. Mol Cell 23: 297-305.

Rathert P, Roth M, Neumann T, Muerdter F, Roe JS, Muhar M, Deswal S, Cerny-Reiterer S, Peter B, Jude J, et al. 2015. Transcriptional plasticity promotes primary and acquired resistance to BET inhibition. Nature 525: 543-547.

Roe JS, Mercan F, Rivera K, Pappin DJ, Vakoc CR. 2015. BET bromodomain inhibition suppresses the function of hematopoietic transcription factors in acute myeloid leukemia. $\mathrm{Mol}$ Cell 58: 1028-1039.

Rosenbauer F, Tenen DG. 2007. Transcription factors in myeloid development: Balancing differentiation with transformation. Nat Rev Immunol 7: 105-117.

Sandberg ML, Sutton SE, Pletcher MT, Wiltshire T, Tarantino LM, Hogenesch JB, Cooke MP. 2005. c-Myb and p300 regulate hematopoietic stem cell proliferation and differentiation. Dev Cell 8: $153-166$.

Sano Y, Ishii S. 2001. Increased affinity of c-Myb for CREBbinding protein (CBP) after CBP-induced acetylation. J Biol Chem 276: 3674-3682.

Schlottmann S, Erkizan HV, Barber-Rotenberg JS, Knights C, Cheema A, Uren A, Avantaggiati ML, Toretsky JA. 2012. Acetylation increases EWS-FLI1 DNA binding and transcriptional activity. Front Oncol 2: 107.

Shen C, Vakoc CR. 2015. Gain-of-function mutation of chromatin regulators as a tumorigenic mechanism and an opportunity for therapeutic intervention. Curr Opin Oncol 27: 5763.

Shen C, Ipsaro JJ, Shi J, Milazzo JP, Wang E, Roe JS, Suzuki Y, Pappin DJ, Joshua-Tor L, Vakoc CR. 2015. NSD3-short is an adaptor protein that couples BRD4 to the CHD8 chromatin remodeler. Mol Cell 60: $847-859$.

Shi J, Vakoc CR. 2014. The mechanisms behind the therapeutic activity of BET bromodomain inhibition. Mol Cell 54: 728736.

Shi J, Whyte WA, Zepeda-Mendoza CJ, Milazzo JP, Shen C, Roe JS, Minder JL, Mercan F, Wang E, Eckersley-Maslin MA, et al. 2013. Role of SWI/SNF in acute leukemia maintenance and enhancer-mediated Myc regulation. Genes Dev 27: $2648-2662$.

Shi J, Wang Y, Zeng L, Wu Y, Deng J, Zhang Q, Lin Y, Li J, Kang T, Tao M, et al. 2014. Disrupting the interaction of BRD4 with diacetylated Twist suppresses tumorigenesis in basal-like breast cancer. Cancer Cell 25: 210-225.

Shi J, Wang E, Milazzo JP, Wang Z, Kinney JB, Vakoc CR. 2015. Discovery of cancer drug targets by CRISPR-Cas 9 screening of protein domains. Nat Biotechnol 33: 661-667.

Silverman LR, Demakos EP, Peterson BL, Kornblith AB, Holland JC, Odchimar-Reissig R, Stone RM, Nelson D, Powell BL, DeCastro CM, et al. 2002. Randomized controlled trial of azacitidine in patients with the myelodysplastic syndrome: A study of the cancer and leukemia group B. J Clin Oncol 20: 2429-2440.

Spyropoulos DD, Pharr PN, Lavenburg KR, Jackers P, Papas TS, Ogawa M, Watson DK. 2000. Hemorrhage, impaired hematopoiesis, and lethality in mouse embryos carrying a targeted disruption of the Fli1 transcription factor. Mol Cell Biol 20: $5643-5652$.

Tomita A, Towatari M, Tsuzuki S, Hayakawa F, Kosugi H, Tamai K, Miyazaki T, Kinoshita T, Saito H. 2000. c-Myb acetylation at the carboxyl-terminal conserved domain by transcriptional co-activator p300. Oncogene 19: 444-451.

Wang W, Yao X, Huang Y, Hu X, Liu R, Hou D, Chen R, Wang G. 2013. Mediator MED23 regulates basal transcription in vivo via an interaction with P-TEFb. Transcription 4: 39-51.

Wouters BJ, Delwel R. 2016. Epigenetics and approaches to targeted epigenetic therapy in acute myeloid leukemia. Blood 127: $42-52$

Wu SY, Chiang CM. 2007. The double bromodomain-containing chromatin adaptor Brd4 and transcriptional regulation. $J$ Biol Chem 282: 13141-13145.

Yamamoto H, Kihara-Negishi F, Yamada T, Hashimoto Y, Oikawa T. 1999. Physical and functional interactions between the transcription factor PU.1 and the coactivator CBP. Oncogene 18: 1495-1501.

Yang Z, Yik JH, Chen R, He N, Jang MK, Ozato K, Zhou Q. 2005. Recruitment of P-TEFb for stimulation of transcriptional elongation by the bromodomain protein Brd4. Mol Cell 19: 535-545.

Yokoyama A, Lin M, Naresh A, Kitabayashi I, Cleary ML. 2010. A higher-order complex containing AF4 and ENL family proteins with $\mathrm{P}-\mathrm{TEFb}$ facilitates oncogenic and physiologic MLL-dependent transcription. Cancer Cell 17: 198-212.

Zhang DE, Zhang P, Wang ND, Hetherington CJ, Darlington GJ, Tenen DG. 1997. Absence of granulocyte colony-stimulating factor signaling and neutrophil development in CCAAT enhancer binding protein $\alpha$-deficient mice. Proc Natl Acad Sci 94: $569-574$

Zuber J, Rappaport AR, Luo W, Wang E, Chen C, Vaseva AV, Shi J, Weissmueller S, Fellmann C, Taylor MJ, et al. 2011a. An integrated approach to dissecting oncogene addiction implicates a Myb-coordinated self-renewal program as essential for leukemia maintenance. Genes Dev 25: 1628-1640.

Zuber J, Shi J, Wang E, Rappaport AR, Herrmann H, Sison EA, Magoon D, Qi J, Blatt K, Wunderlich M, et al. 2011b. RNAi screen identifies Brd4 as a therapeutic target in acute myeloid leukaemia. Nature 478: 524-528. 


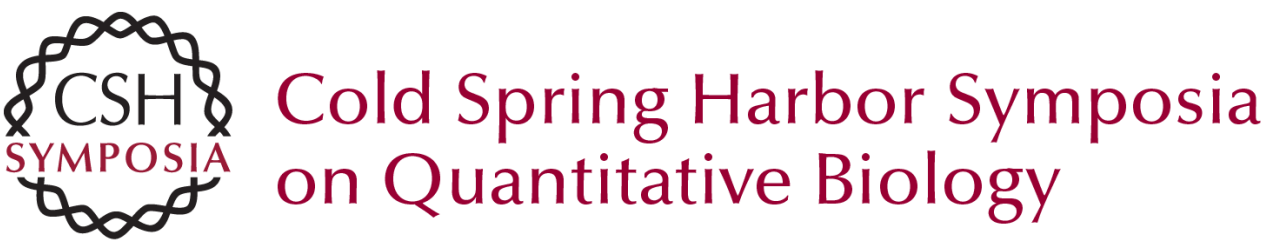

\section{The Essential Transcriptional Function of BRD4 in Acute Myeloid Leukemia}

Jae-Seok Roe and Christopher R. Vakoc

Cold Spring Harb Symp Quant Biol 2016 81: 61-66 originally published online February 7, 2017 Access the most recent version at doi:10.1101/sqb.2016.81.031039

References This article cites 73 articles, 23 of which can be accessed free at: http://symposium.cshlp.org/content/81/61.full.html\#ref-list-1

Creative This article is distributed under the terms of the

Commons http://creativecommons.org/licenses/by-nc/4.0/, which permits reuse and License redistribution, except for commercial purposes, provided that the original author and source are credited.

Email Alerting Receive free email alerts when new articles cite this article - sign up in Service the box at the top right corner of the article or click here. 